\title{
Self-Prophecy Effects and Voter Turnout: An Experimental Replication
}

\author{
Jennifer K. Smith, Alan S. Gerber, and Anton Orlich \\ Department of Political Science, Yale University
}

\begin{abstract}
Psychological research has found that being asked to predict one's future actions can bring about subsequent behavior consistent with the prediction but different from what would have occurred had no prediction been made. In a 1987 study, Greenwald, Carnot, Beach, and Young induced an increase in voting behavior by means of such a "self-prophecy" effect: Undergraduates who were asked to predict whether they would vote in an upcoming election were substantially more likely to go to the polls than those who had not been asked for a prediction. This paper reports on a replication of the Greenwald study conducted among a larger group of respondents more representative of the American electorate. No evidence was found that self-prophecy effects increase voter turnout.
\end{abstract}

KEY WORDS: voter turnout, mobilization, self-prophecy, experiment, replication

An intriguing strand of psychological research suggests that the simple act of predicting one's future behavior has the potential to alter that behavior. This phenomenon has two dimensions: First, individuals tend to "mispredict" their own future actions, in the sense that predictions made by one group of subjects diverge from the actual behavior of a separate but comparable group that did not make a prediction. Second, and more important, these errors appear to be "self-erasing": Having offered a prediction, subjects are more likely to act in accordance with their stated expectations than they would have been in the absence of the prediction (Sherman, 1980). This phenomenon, variously described as the "self-erasing nature of errors of prediction" (Sherman, 1980) and the "self-prophecy effect" (Greenwald, Klinger, Vande Kamp, \& Kerr, 1988; Spangenberg \& Greenwald, 1999, 2001), has been observed with regard to a number of "target behaviors," including visiting a health club (Spangenberg, 1997), refraining from cheating on an exam (Spangenberg \& Obermiller, 1996), and volunteering for the American 
Cancer Society (Sherman, 1980). ${ }^{1}$ Several psychological mechanisms have been offered to account for the apparent efficacy of this intervention. In the first paper on the subject, Sherman suggested that "prediction of a behavioral sequence evokes a specific cognitive representation of that sequence, which is accessed on subsequent occasions" and leads to conformity with the prediction (1980, p. 211). A more recent interpretation relates self-prophecy to the theory of cognitive dissonance, suggesting that prediction errors may be observed to self-correct as subjects attempt to resolve an induced discrepancy between self-concept and behavior (Spangenberg \& Greenwald, 1999, 2001, citing Aronson, 1992). This explanation appears more consistent with recent empirical evidence on self-prophecy (Spangenberg \& Greenwald, 2001) than does Sherman's hypothesis.

The act of voting represents a particularly good test of the hypothesis that errors of prediction are self-erasing. Studies of voting naturally conform to the requirement that the prediction and behavior phases of an experiment be physically and psychologically separated (Sherman, 1980). Turnout studies have the further advantage that researchers need not construct an artificial context within which subjects' self-predictions may be confirmed or refuted. Finally, information on voting behavior is easily acquired from public records, and it is therefore not necessary to rely on individuals' reports of their own actions.

In a 1987 study, Greenwald, Carnot, Beach, and Young investigated the effect of self-prediction on voting behavior. Greenwald et al. reported considerable success in increasing voter turnout by means of a simple telephone poll conducted shortly before a general election. When registered voters were asked to predict whether they would vote in the upcoming election, the turnout rate among those offering a prediction was 25 percentage points higher than turnout in a control group of registrants who were contacted by the investigators but not asked to make a prediction $(61.5 \%$ vs. $86.7 \%)$. On the strength of this finding, Greenwald et al. expressed hope that the self-prophecy effect might be exploited to influence turnout levels more broadly: "For example, if one could call 10,000 voters who could be counted on to vote for one's preferred candidate, an effect of the strength observed in [our experiment] would increase that candidate's vote total by about 2,500 votes" (1987, p. 318).

The potential political implications of the Greenwald et al. finding, together with researchers' success in inducing self-prophecy effects in a variety of other contexts, makes the question of whether voter turnout can be increased through the self-prediction mechanism well worth the professional attention of political scientists. The finding of Greenwald et al. merits replication in a larger sample of registered voters more representative of the general U.S. population. To reassess

\footnotetext{
${ }^{1}$ A related self-prophecy phenomenon, the "mere measurement effect," has been described by Morwitz, Johnson, and Schmittlein (1993). Morwitz et al. found that simply asking subjects whether they intended to make a durable-goods purchase in the future resulted in a slightly increased propensity to buy.
} 
the political implications of self-prophecy, we carried out a replication experiment during a presidential primary election in March 2000.

\section{Method}

The experiment was conducted in a southern New England town of around 50,000 residents. We began by identifying a random sample of all households of one or two registered voters. Because the election being studied was a closed primary, participation was further restricted to registered Democrats and Republicans residing in these households. Eligible respondents were contacted by telephone on the Sunday and Monday evenings immediately preceding the 7 March 2000 presidential primary. Calling took place from 4 to 6 p.m. and from 7 to 9 p.m. Sunday and from 6 to 9 p.m. Monday. The experiment was conducted by 24 interviewers, primarily graduate students, who were paid \$25 per hour; callers completed 718 interviews on Sunday afternoon and evening and 442 on Monday. ${ }^{2}$ Because the experiment was restricted to registered voters with a major-party affiliation residing in a single city, the respondents do not-as would ideally be the case-constitute a random sample of the entire U.S. population. However, the experimental sample was both larger and more representative of the voting public than the sample of 60 college undergraduates investigated by Greenwald et al. (1987). ${ }^{3}$

As each household was contacted, the interviewer asked to speak with the person whose name was listed first on the contact sheet provided by the researchers (the order of names on this sheet was also randomized). If this individual was absent or unavailable, the interviewer proceeded (where applicable) to ask for the second person. If no listed respondent resided at the number called, the interview was terminated. Once an eligible respondent was identified, interviewers read the following introduction: ${ }^{4}$

${ }^{2}$ Greenwald et al. (1987) administered their experimental treatment on the Monday before the election, and we were careful to follow them as closely as possible with respect to timing. Respondents who were contacted either Sunday or Monday but requested that the interviewer call back at another time were recontacted Monday evening as time allowed. In addition, on Monday callers were instructed (again as time permitted) to make a second attempt to reach those numbers for which a first call had resulted in no answer, a busy signal, or an answering machine. No messages were left on respondents' answering machines.

${ }^{3}$ Because we have no demographic data on residents of Ohio State University dormitories in 1984 (the population on which the original Greenwald study drew), this statement is necessarily somewhat speculative. It is certain, however, that our sample is considerably more representative of the U.S. population with respect to age and educational attainment than the sample studied by Greenwald et al.

${ }^{4}$ The portions of the interview text shown in italics were adopted directly from the protocol provided in Greenwald et al. (1987). We have followed their model as closely as possible, making changes to the text they provide only in the introductory request for participants' consent. (Our interviewers could not state that they were conducting the interviews as part of a class project, and we did not ask respondents to provide their names.) 
My name is [interviewer's first name], and I'm conducting a university research survey of registered voters. You can help us a lot by answering just a few questions about voter knowledge. I'm not selling anything, and I will not be asking for any information about your preferences among the candidates or how you will be voting. The entire questionnaire will take less than three minutes to complete, and your answers will be confidential. Can you take a moment to answer this survey?

Following Greenwald, callers then asked whether the respondent knew the location of his or her polling place and the hours during which it would be open for the primary election. Respondents who did not know their polling place's hours of operation were provided with the correct information. After this preliminary stage of the survey was completed, respondents were randomly sorted into a control condition and three distinct treatment conditions. Callers performed the randomization by drawing one playing card from a well-shuffled deck provided by the investigators; the suit of the card indicated the condition to which the respondent was to be assigned. ${ }^{5}$ For respondents assigned to the control condition, the caller terminated the interview after asking two demographic questions (these questions were also appended to the three experimental interviews).

\section{Experimental Treatments}

Although Greenwald et al. described their experimental treatment as simply asking individuals to predict whether they would vote, the treatment actually administered was somewhat more complex. After respondents had predicted their behavior, those who predicted that they would vote (100\% of the Greenwald treatment group) were asked to name the "most important single reason" for voting (1987, p. 316). Greenwald et al. argued that having respondents provide reasons for a behavior should increase the likelihood of compliance with self-predictions. They did not view the additional question as materially altering the treatment; rather, they saw this prompt as reinforcing the effectiveness of the true experimental treatment, the prediction. This belief is supported by a recent study showing that providing a reason for voting increased the likelihood that young adults would adhere to a signed pledge to vote (Burgess, Haney, Snyder, Sullivan, \& Transue, 2000). However, other research suggests that being asked to supply reasons for one's behavior may "disrupt" choice and make respondents

\footnotetext{
${ }^{5}$ We examined the quality of the randomization procedure with the use of data on respondents' prior voting histories. There was no relationship between voting in the previous five general elections and assignment to experimental condition $\left[\chi^{2}(20)=23.9, \mathrm{p}=.25\right]$.
} 
Table 1. Summary of Experimental Design

\begin{tabular}{lcccc}
\hline Condition & $\begin{array}{c}\text { Respondent } \\
\text { contacted by } \\
\text { researchers }\end{array}$ & $\begin{array}{c}\text { Respondent } \\
\text { asked about } \\
\text { precinct location } \\
\text { and polling hours }\end{array}$ & $\begin{array}{c}\text { Respondent } \\
\text { asked to predict } \\
\text { whether he/she } \\
\text { would vote }\end{array}$ & $\begin{array}{c}\text { Respondent } \\
\text { asked to provide } \\
\text { a reason for } \\
\text { voting }\end{array}$ \\
\hline $\begin{array}{l}\text { Control } \\
\text { Prediction only }\end{array}$ & Yes & Yes & No & No \\
$\begin{array}{l}\text { Reason only } \\
\text { Prediction and }\end{array}$ & Yes & Yes & Yes & No \\
reason & Yes & Yes & Yo & Yes \\
\hline
\end{tabular}

less likely to behave in predictable ways or as they otherwise would have (Wilson, Dunn, Kraft, \& Lisle, 1989; Wilson \& Schooler, 1991). Although the treatment administered by Greenwald et al. (1987) conflates the potentially complex reason-giving effect with the self-prophecy effect, our replication disentangles the two.

To better assess the impact of the dual treatment applied by Greenwald et al., we incorporated three experimental conditions in our study: a compound treatment following the Greenwald text, and two treatments breaking the compound down into its constituent elements. Respondents in one treatment condition were asked only to predict whether they would vote; those in a separate condition were asked only to provide the most important reason for voting. The interview for respondents assigned to the compound treatment proceeded as follows:

What do you expect to do between now and the time the polls close tomorrow [or Tuesday]? Do you expect that you will vote, or not?

Following the Greenwald protocol, respondents who replied that they didn't know whether they would vote were pressed to respond one way or the other:

We would like you to predict your action in any case. Do you think you will vote or not?

Callers completed the interview by asking:

What would you say is the most important single reason for voting?

and recording the interviewee's response. The same interview text-restricted to either the self-prediction or reason-giving portions-was used for respondents in the other two treatment conditions. A summary of the experimental design is presented in Table 1. 
Table 2. Experimental Results

\begin{tabular}{llcr}
\hline Condition & \multicolumn{2}{c}{ Did respondent vote? } & Total \\
\cline { 2 - 4 } & \multicolumn{2}{c}{ Yes } & No \\
\hline Control & $125(43.4 \%)$ & $163(56.6 \%)$ & 288 \\
Prediction only & $130(43.3 \%)$ & $170(56.7 \%)$ & 300 \\
Reason only & $118(39.2 \%)$ & $183(60.8 \%)$ & 301 \\
Prediction and reason & $118(43.5 \%)$ & $153(56.5 \%)$ & 271 \\
Total & 491 & 669 & 1,160 \\
\hline
\end{tabular}

\section{Results}

Several weeks after the election, we collected voting data for each participant in the experiment. Table 2 summarizes the observed behavior of the respondents assigned to each condition. ${ }^{6}$

Of the 288 individuals in the control group, 125 (43.4\%) voted on election day. Among the 271 respondents assigned to the dual "prediction and reason" condition, 118 (43.5\%) turned out to vote. Whereas Greenwald et al. (1987) obtained a 25.2 - percentage point increase in voter turnout among respondents receiving the compound treatment (from $61.5 \%$ to $86.7 \%$ ), we observe a 0.1 -point increase - a barely perceptible shift. Moreover, because the base level of turnout was higher in the Greenwald et al. study than in ours, the potential role of "ceiling effects" implies that it should have been easier for us to observe an experimental

\footnotetext{
${ }^{6}$ Note that Table 2 does not divide respondents according to whether the prediction they made was "Yes" or "No." Separating respondents predicting Yes from those predicting No-and comparing the voting behavior of the Yes group with the experimental control group-would conflate a possible experimental effect with the unobserved differences across respondents answering Yes and No within the experimental groups. If respondents predicting No outnumbered those predicting Yes, the self-prophecy effect might conceivably have operated in the opposite direction from that anticipated. However, a substantial majority of our treatment respondents predicted Yes. [Of 571 respondents asked to predict their voting behavior, 555 (97.2\%) offered a prediction at either the first or second stage of the request-and-follow-up procedure adopted from Greenwald et al. (1987); 460 respondents $(82.9 \%$ of those making some prediction) predicted Yes, and 95 said No. The Yes-prediction rate for the Greenwald et al. (1987) study was $100 \%(N=32)$; in a replication experiment, Greenwald et al. (1988) reported Yes-predictions from $82.7 \%$ of 154 respondents making a prediction. The latter figure is quite similar to our own rate of Yes-prediction.] With a net majority of over $60 \%$ predicting they would vote, a self-prophecy effect should have been evident in our data if its magnitude were even a fraction of the effect sizes reported in previous studies. If the self-prophecy mechanism operated in a sharply asymmetric fashion-that is, if predicting No strengthened respondents' disinclination to vote far more than predicting Yes did their inclination- there might be unobserved self-prophecy effects lurking in our data. However, previous studies of self-prophecy, among which the Greenwald et al. (1987) rate of $100 \%$ Yes-prediction is exceptional, do not assume and have not established the existence of any such dramatic asymmetry in self-prophecy effects. Our implicit assumption that the effect of a No prediction is at least no greater than the effect of a Yes prediction is reasonable given the current state of knowledge about self-prophecy.
} 
effect if one were present. ${ }^{7}$ The possibility that we obtain a null result because of the complicating effect of asking for reasons is ruled out by the result for the "prediction only" condition. These respondents, who were exposed only to the selfprophecy treatment, turned out at a rate fractionally lower than that observed in the compound and control conditions: $43.3 \%$. The only respondents for whom we observed an apparent change in behavior were those in the "reason only" condition, and this group's turnout rate moved in the wrong direction (39.2\% turnout vs. $43.4 \%$ for the control group).

Statistical analysis shows that voter turnout was not meaningfully increased by any of our experimental treatments. For none of the three treatment conditions did the experimental group's turnout rate differ significantly from that of the control group in the predicted direction: The $\chi^{2}$ statistic $(1.63,3 \mathrm{df})$ has a $p$ value of .65 , and one-tailed $t$ tests for each treatment yield $p$ statistics ranging from .49 to .85. Differences of the magnitude we observe can easily be attributed to chance variation. This result contrasts with the finding of Greenwald et al. (1987), who obtained a statistically significant increase in voter turnout for the experimental group $\left(p<.05, \chi^{2}\right.$ test $)$.

Our confidence in this null finding is strengthened by the fact that the statistical power of the experiment should have been sufficient to detect a self-prophecy effect if one were present. In a meta-analysis of the self-prophecy literature, Spangenberg and Greenwald (2001) found an average effect size in 15 studies of 13.2; when three experiments whose authors offered compelling theoretical or methodological reasons for their failure to find significant self-prophecy effects were excluded, the average effect size in the remaining 12 studies was $19.3 \%$ (2001, p. 54). To calculate power, we compared our control group $(\mathrm{N}=288)$ with the combined sample for the two treatments incorporating a prediction $(\mathrm{N}=300$ $+271=571)$. The power of a $5 \%$ test versus the alterative hypothesis of a $13.2 \%$ effect is .98; versus a $19.3 \%$ effect, the power is $>.99$.

\section{Effect of Prior Turnout Behavior}

In a 1988 paper, Greenwald, Klinger, Vande Kamp, and Kerr suggested that there may be limits to the conditions under which self-prophecy effects can be experimentally induced that were not identified by Greenwald et al. (1987). Specifically, they argued that individuals with an especially strong or weak past record of engaging in the behavior to be predicted are unlikely to be moved by requests for self-prophecy. Thus, self-prophecy effects are unlikely to be observed either among persons who almost always vote or among those who almost never

\footnotetext{
${ }^{7}$ Greenwald et al. (1988, p. 4) suggested that precisely such a "ceiling effect" was responsible for the failure of a similar experimental treatment to induce a self-prophecy effect in a 1986 Washington senatorial election (control group turnout was $87 \%$ ).
} 
do. ${ }^{8}$ Individuals whose record of engaging in the activity in the absence of experimental intervention is moderate, however, are more likely to be swayed by selfprophecy. Greenwald et al. (1988) reported empirical evidence in support of this contention from a turnout experiment conducted before a state legislative primary. Among respondents whose level of prior voter turnout was "moderate," selfprophecy had a statistically significant effect on voting behavior $(p<.01)$. For this subgroup, voter turnout was $52.2 \%$ in a "prediction" condition $(N=23)$ and $66.7 \%$ in a "prediction and reason" condition $(N=18)$, as against an average of $33.9 \%$ in two control groups $(N=59)$. Pooling the two treatment groups, the turnout level was $58.5 \%$-almost 25 percentage points higher than for the control conditions. Among low- and high-prior-turnout respondents, the experimental treatments had no significant effect on voting.

We were able to use the present experiment to explore the hypothesis that respondents' prior history of engaging in the action to be predicted may be an important conditioning factor in the operation of self-prophecy. Following Greenwald et al. (1988), we obtained voter turnout data for the five general elections preceding the presidential primary at which our experiment was conducted (the elections of November 1995 to November 1999). When these data were merged with our experimental data file, we were able to obtain matches for 1,152 of 1,160 respondents. Those who had voted in zero, one, or two of the five elections were classified as "low prior turnout," those who had voted in three or four elections as "moderate prior turnout," and those voting in all five elections as "high prior turnout." Table 3 presents a reanalysis of our experimental data, broken down by respondents' levels of prior voting behavior.

The striking variation in voting rates across the columns of Table 3 indicates that respondents who had voted in previous elections were correspondingly more

\footnotetext{
${ }^{8}$ Likely explanations for the absence of self-prophecy effects differ for these two groups. Among highturnout voters, the influence of self-prophecy may not be perceptible because of a ceiling effect (Greenwald et al., 1988; Spangenberg \& Greenwald, 1999). Low-turnout voters, on the other hand, may be immune to the desire for positive self-presentation created by an interviewer's request for self-prophecy (Greenwald et al., 1988, p. 10), or they may not experience dissonance associated with the act of not voting. Alternatively, the practical barriers that prevent the self-prophecy impulse from being realized in voting behavior may be too high.

${ }^{9}$ This classification differs somewhat from that used by Greenwald et al. (1988). Greenwald et al. assigned respondents who had voted in one or two of the five earlier elections for which turnout data were gathered to the low-prior-turnout category, those voting in three elections to the moderate-priorturnout category, and those voting in four or in all five elections to the high-prior-turnout group (1988, p. 9). (They did not indicate whether any of their respondents were found to have voted in none of the five elections.) Because this classification scheme creates a striking numerical imbalance between the low-, moderate-, and high-prior-turnout categories in our study, we report results for an alternate classification here. However, the substance of our finding - that there is no evidence for a significant experimental treatment effect conditional on moderate (or any other level of) prior turnout - is unchanged when the original Greenwald et al. (1988) classification method is applied to our data. We also tested a number of alternative classifications, including using six separate categories denoting participation in 0 to 5 prior elections. None of these alternatives yields even a marginally significant effect of prior voting behavior on experimental outcomes.
} 
Table 3. Experimental Results Conditional on Prior Voting Behavior

\begin{tabular}{lcccc}
\hline Condition & $\begin{array}{c}\text { Did respondent } \\
\text { vote? }\end{array}$ & \multicolumn{2}{c}{ Respondent's prior voting behavior } \\
\cline { 2 - 5 } & & Low & Moderate & High \\
\hline Control & Yes & 22 & 42 & 60 \\
& No & 71 & 56 & 35 \\
Prediction only & Percent voting & $23.7 \%$ & $42.9 \%$ & $63.2 \%$ \\
& Yes & 32 & 46 & 52 \\
Reason only & No & 67 & 60 & 41 \\
& Percent voting & $32.3 \%$ & $43.4 \%$ & $55.9 \%$ \\
Prediction and reason & Yes & 19 & 55 & 44 \\
& No & 78 & 64 & 38 \\
& Percent voting & $19.6 \%$ & $46.2 \%$ & $53.7 \%$ \\
Total $(N=1,152)$ & Yes & 19 & 42 & 57 \\
& Percent voting & $23.8 \%$ & 52 & 39 \\
\hline
\end{tabular}

Note. Respondents who had voted in zero, one, or two of the previous five general elections were classified as "low prior turnout," those voting in three or four elections as "moderate prior turnout," and those voting in all five as "high prior turnout." Eight respondents could not be identified in the voter-history data file; thus, $N=1,160-8=1,152$.

likely to vote in the election studied. However, the data in Table 3 do not show that the effectiveness of the experimental treatments varied significantly by respondents' rates of turnout in prior elections. It is true that, for moderateprior-turnout respondents, turnout in all three experimental conditions was higher than in the control condition (something that does not hold for low- or highprior-turnout respondents), but the magnitude of the observed differences is small and can easily be explained by chance variation. ${ }^{10}$ No pattern emerges to suggest that any one group of voters was peculiarly susceptible to the influence of requests for prediction, or that one treatment was consistently more effective than the others. Also, the amount of variation between the prior-turnout categories is greater than the variability observed within any one of them. In contrast to Greenwald et al. (1988), the highest turnout rate we observed among moderateprior-turnout respondents did not exceed the voting rate of any group of highprior-turnout respondents.

\section{Conclusions}

This replication of the Greenwald et al. (1987) experiment yields no evidence that the self-prophecy effect-whatever its value in inducing other behavior

${ }^{10}$ This is evident from $\chi^{2}$ tests performed on the data shown in Table 3. For low-prior-turnout voters, $\chi^{2}(3)=4.51, p=.21$. For moderate-prior-turnout respondents, $\chi^{2}(3)=0.30, p=.96$, and for the high-prior-turnout group, $\chi^{2}(3)=1.91, p=.59$. 
modifications - can generate substantial increases in voter turnout. Our findings cast doubt on the optimistic assessment of self-prophecy's political implications endorsed by Greenwald et al., and suggest some perspective on why Greenwald et al. obtained the result they did. We suspect that the striking effect reported by Greenwald et al. is more likely to have resulted from a small and unrepresentative sample or chance variation in turnout than from any peculiar effectiveness of the self-prophecy treatment. This suspicion is consistent with the fact that Greenwald's own replication of the 1987 experiment produced only mixed support for the published finding (Greenwald et al., 1988).

An alternative possibility is that the diverse election contexts in which self-prophecy has been investigated - a general election in a presidential year (Greenwald et al., 1987), an off-year Senate race (Greenwald et al., 1988), a Democratic primary in a state legislative contest (Greenwald et al., 1988), and a "Super Tuesday" presidential primary (the present study) - may have unrecognized significance for the operation of self-prophecy effects, perhaps accounting for the failure of the effect to manifest itself in our experiment. However, we see no reason to believe that voters in the election we studied should have been peculiarly resistant to the influence of self-prophecy. Certainly none of the theoretical explanations proposed for the self-prophecy effect implies that the effect would not extend to presidential primaries.

Beyond its pessimistic conclusion about the possibility of substantial selfprophecy effects on voter turnout, our experiment also contributes to a developing understanding of the efficacy of telephone contact in increasing voter turnout. Previous randomized experiments have sought to stimulate turnout by means of telephone calls delivering different sorts of messages in a variety of electoral contexts. Although some researchers have reported turnout increases of 15 percentage points and more (Eldersveld, 1956; Miller, Bositis, \& Baer, 1981), these studies, like the Greenwald experiment, rely on samples that are too small to permit much certainty about the true magnitude of the observed effect. ${ }^{11}$ Research conducted with larger samples of registered voters suggests a more measured view of the potential role of telephone contact in encouraging voter turnout. In an experiment conducted before a city council by-election in Washington, D.C., Adams and Smith (1980) observed a 9-point turnout increase among voters who had been contacted by a professional firm, reminded of the upcoming election, and urged to vote for a particular candidate. By contrast, Gerber and Green $(2000,2001)$ were unable to generate higher turnout among respondents who received nonpartisan telephone appeals from professional callers before the general election of 1998. Whereas the experimental manipulations of Gerber and Green $(2000,2001)$ and Adams and Smith (1980) involved asking or imploring individuals to vote, the self-prophecy mechanism takes the quite different approach of inviting indi-

${ }^{11}$ Eldersveld contacted 33 respondents and Miller et al. 39. Although the effect sizes obtained in these experiments are dramatic, they fall short of statistical significance because of the small sample size. 
viduals to predict their future behavior while making no attempt to persuade. In contrast to Greenwald et al. (1987, 1988), we find no indication that the selfprophecy message is particularly effective in stimulating turnout.

Given the findings of these larger-sample studies, it appears unlikely that telephone contact can induce increases in turnout on the order of that originally reported by Greenwald et al. (1987), at least using the techniques that have been proposed to date. However, the tension between the positive result obtained by Adams and Smith (1980) and the null findings of Gerber and Green $(2000,2001)$ and our own experiment suggests the need for further exploration of the particular conditions under which telephone contact may produce measurable increases in voter turnout. It would be particularly interesting to consider whether the variation in observed effects—should it be substantiated by future research-reflects the content of the message delivered (such as its partisan or nonpartisan character) or the context of the election in which the experiment was performed (such as the base level of voter turnout). Blandishments and prophecies must doubtless move some voters some of the time; the task ahead is to identify who and when.

\section{ACKNOWLEDGMENTS}

We thank Donald Green, Vicki Morwitz, and the anonymous reviewers for valuable comments on previous drafts of this paper. Correspondence concerning this article should be sent to Jennifer Smith, Department of Political Science, Yale University, P.O. Box 208301, New Haven, CT 06520-8301. E-mail: jennifer.smith@yale.edu

\section{REFERENCES}

Adams, W. C., \& Smith, D. J. (1980). Effects of telephone canvassing on turnout and preferences: A field experiment. Public Opinion Quarterly, 44, 389-395.

Aronson, E. (1992). The return of the repressed: Dissonance theory makes a comeback. Psychological Inquiry, 3, 303-311.

Burgess, D., Haney, B., Snyder, M., Sullivan, J. L., \& Transue, J. E. (2000). Rocking the vote: Using personalized messages to motivate voting among young adults. Public Opinion Quarterly, 64, $29-52$.

Eldersveld, S. J. (1956). Experimental propaganda techniques and voting behavior. American Political Science Review, 50, 154-165.

Gerber, A. S., \& Green, D. P. (2000). The effects of canvassing, telephone calls, and direct mail on voter turnout: A field experiment. American Political Science Review, 94, 653-663.

Gerber, A. S., \& Green, D. P. (2001). Do phone calls increase voter turnout? A field experiment. Public Opinion Quarterly, 65, 75-85.

Greenwald, A. G., Carnot, C. G., Beach, R., \& Young, B. (1987). Increasing voting behavior by asking people if they expect to vote. Journal of Applied Psychology, 2, 315-318.

Greenwald, A. G., Klinger, M. R., Vande Kamp, M. E., \& Kerr, K. L. (1988). The self-prophecy effect: Increasing voter turnout by vanity-assisted consciousness raising. Unpublished manuscript, University of Washington. 
Miller, R. E., Bositis, D. A., \& Baer, D. L. (1981). Stimulating voter turnout in a primary: Field experiment with a precinct committeeman. International Political Science Review, 2, 445-460.

Morwitz, V. G., Johnson, E., \& Schmittlein, D. (1993). Does measuring intent change behavior? Journal of Consumer Research, 20, 46-61.

Sherman, S. J. (1980). On the self-erasing nature of errors of prediction. Journal of Personality and Social Psychology, 39, 211-221.

Spangenberg, E. R. (1997). Increasing health club attendance through self-prophecy. Marketing Letters, 8, 23-32.

Spangenberg, E. R., \& Greenwald, A. G. (1999). Social influence by requesting self-prophecy. Journal of Consumer Psychology, 8, 61-89.

Spangenberg, E. R., \& Greenwald, A. G. (2001). Self-prophecy as a behavior modification technique in the United States. In W. Wosinska, R. B. Cialdini, D. W. Barrett, \& J. Reykowski (Eds.), The practice of social influence in multiple cultures (pp. 51-62). Mahwah, NJ: Erlbaum.

Spangenberg, E. R., \& Obermiller, C. (1996). To cheat or not to cheat: Reducing cheating by requesting self-prophecy. Marketing Education Review, 6, 95-103.

Wilson, T. D., Dunn, D. S., Kraft, D., \& Lisle, D. J. (1989). Introspection, attitude change, and attitude-behavior consistency: The disruptive effects of explaining why we feel the way we do. Advances in Experimental Social Psychology, 22, 287-343.

Wilson, T. D., \& Schooler, J. W. (1991). Thinking too much: Introspection can reduce the quality of preferences and decisions. Journal of Personality and Social Psychology, 60, 181-192. 